\title{
Study on the Construction of Multimodal Interactive Oral English Teaching Model
}

\author{
Yi Yang \\ Baoding College, Baoding, China \\ Email: same512@163.com
}

How to cite this paper: Yang, Y. (2018). Study on the Construction of Multimodal Interactive Oral English Teaching Model. Open Journal of Modern Linguistics, 8, 137-142.

https://doi.org/10.4236/ojml.2018.84014

Received: June 24, 2018

Accepted: August 20, 2018

Published: August 23, 2018

Copyright $\odot 2018$ by author and Scientific Research Publishing Inc. This work is licensed under the Creative Commons Attribution International License (CC BY 4.0).

http://creativecommons.org/licenses/by/4.0/

\begin{abstract}
There are many factors influencing the effect of college oral English teaching. The main problems in college English teaching are as follows: the current teachers' teaching cannot meet the needs of students; students have low self-efficacy in oral English study; the foreign language teaching environment is not perfect enough. Based on multimodal discourse theory, teachers should integrate the current methods and strategies of college oral English teaching, construct the multimodal oral English teaching model, improve college oral English teaching and promote college students' oral English communication skills.
\end{abstract}

\section{Keywords}

Oral English Teaching, Multimodal Course, Teaching Mode

\section{Introduction}

With the development of the times, the oral English ability of college graduates is widely valued by employers. However, many college students still can't speak good English after years of study. Environment differences, cultural differences and psychological anxieties are factors that hinder college students' English learning and oral communication. In order to create a light, relaxed and pleasant learning environment for college students, the multimodal oral teaching model is an optimal choice. One of the most popular research topics in the past decade in Europe and America is multimodal discourse analysis and the application of multimodal discourse in teaching. Among them, Kress and Vanleeuwen take Halliday's systemic functional linguistics as the theoretical foundation (Kress \& Leeuwen, 1996). They advocate that discourse analysis should pay attention to other forms of social signs, such as images, actions, sounds and colors, rather 
than the language itself. They also think that modality is the mode or way of communicating information between people or people and machines under the influence of some medium. Through grammar framework of visual image, they construct the analysis method and lay theoretical basis for multimodal discourse analysis: the concept of "multimodal teaching" was proposed in 1996 by New London Group. This new teaching idea holds the opinion that teachers should use a variety of teaching methods including pictures, network, role-play to mobilize different senses of learners to participate in collaborative operation of language learning, and cultivate multi-abilities of learners (New London Group, 1996).

\section{The Necessity of Multimodal Teaching in Oral English}

In the current teaching practice of college English, though it has been put forward for many years centered on college students, which teachers are also striving to develop toward this direction, teachers still play a central role. The current methods of improving college students' oral English tend to allow them to do a lot of oral exercises to enhance their oral fluency and sense of communication. Although this kind of single speaking mode of training can overcome the problem of fluency, college students can't improve their own ability of grammar, sentence patterns and vocabulary. In this way, the overall quality of college students' oral English can hardly be improved. Therefore, the combination of multimodal teaching methods is more convenient for learners to understand and memorize than traditional single modality teaching mode, which can also improve college students' oral comprehensive ability more effectively. Nowadays, more and more multimodalities are involved in courses, such as multimedia courseware, including visual and auditory modality; scene simulation and explanation may be carried on simultaneously with vision, hearing and touch (Zhu, 2007). The rational use of multimodal can create a harmonious ecological environment and stimulate the initiative of college students and to the maximum extent to exercise and improve college students' oral English and teamwork ability $(\mathrm{Gu}, 2007)$.

\section{Multimodal Symbols and the Coordination between Multimodals}

In oral English teaching, we should use the auditory, visual, language and other modes. In college English class, teachers' tone, expression, movement, gesture, dress and classroom tools such as PPT, blackboard, chalk, etc. all belong to modal symbols, which play important roles in the construction of the meaning of the whole class.

1) Auditory modal symbols

The auditory modal is the most commonly used method in oral classroom teaching. In oral English class, teachers' meta-language symbols and college students' spoken language symbols are the most important symbols of hearing 
mode, which may include multimedia electronic audio symbols or music symbols, and even the noise outside the classroom etc.

2) Visual modal symbols

Compared with the important position of auditory symbols in oral English classroom, visual modal is relatively auxiliary, but its complementary function can't be ignored. In modern English class, visual modal symbols are relatively abundant, such as the teacher's blackboard writing and written language symbols presented by the PPT text, pictures and video image symbols; body movements, facial expressions and eye contact, body language symbols between teachers and students and classroom size, positions of tables and chairs are all visual semiotics.

3) Other modal symbols

In addition to auditory modality and visual modality, there are also human sensory modalities, such as smell, touch and taste. These modal symbols are not used in English teaching at present, but they can be tried in particular situation (Li, 2003). For example, on some specific occasions, they can pass the messages with help of flowers, fruits, food and so on. The proper selection of these modal symbols can enrich the authenticity and vividness of the oral English class.

4) The coordination between multimodals

Culture is rooted in language, and multimodal teaching method can effectively combine cultural connotation and language learning. Take drama performance-a common form of activity in English class as an example. Through rehearsing plays, students can experience the emotions of the characters and then express them in their own ways, which can not only practice their oral English, but also test their expressiveness and infectivity. Students' drama performances include static resources such as costumes, hairstyles and props, as well as dynamic resources such as voices, expressions and actions. This kind of real language environment can help them get rid of the hindrance of their native language thinking mode, mobilize the comprehensive response of the senses and brain to language information, and naturally absorb language. At the same time, the fusion of audio-visual gives students a comprehensive and multi-sensory experience, which can better convey the cultural connotation of language to students and cultivate their communicative ability of multimodal discourse.

\section{The Methods to Realize the Multimodal Teaching of Oral English}

1) Teachers' training

In the process of classroom teaching, teachers will affect directly or indirectly on college students' language input, through verbal or non-verbal output. As we mentioned earlier, the auditory modality is the main mode of teaching in the oral English classroom, which makes a high demand for the teacher's discourse quality. First of all, teachers should take part in related professional courses, strengthen theoretical guidance, and improve their theoretical literacy and mul- 
timodal oral teaching ability. Secondly, teachers should strive to improve their speaking ability and use accurate pronunciation and intonation. In addition, teachers should complement and strengthen their discourse meaning through visual modal symbols such as movements, gestures and facial expressions, in order to cultivate college students' multimodal oral communicative competence.

Finally, teachers should learn more from peers and organize more oral class activities, such as speeches, debates and role play, so as to make college students become the transmitter of auditory and visual modality.

2) Multi modality of multimedia applications

Multimedia has been widely used in teaching, such as PPT, slide, human-computer dialogue, network courses and so on. First of all, the multimedia courseware is applied in college English teaching. Through the tasks which are reasonable designed and of strong pertinence and operability, the sound, images and symbols are used in the classroom teaching to increase the amount of information, combining with the environment, and achieving the best teaching effect. Using a fixed template to make PPT through multimedia, you can paste or link the text, picture, audio and video according to your own needs. Teachers can design courseware freely and independently according to their own willingness, and can also update them in a timely manner and continue to apply the latest information and research results in teaching. Second, teachers should actively use the internet and multimedia equipments, and collect extensively related teaching content of the real scene images, audio and video materials with pure tone and positive attitude, in order to give college students direct feelings, and fully mobilize all the senses of theirs.

3) The multimodality of teaching objects

a) Multi-modality of teaching environment. The classroom can be arranged in accordance with the conditions of the school, so that the teachers can realize the modality of oral English class through PPT or other media. In addition, the seat arrangement in the oral English class can be referred to the foreign class $\mathrm{O}$ or $\mathrm{U}$ type. In this way, each student has a relatively fair opportunity to be concerned by the teachers, which also helps college students to exhibit in the middle or discuss with their fellow peers. Finally, teachers should help college students to create more multi-modal oral learning platforms, such as English corner, English salon, and English evening parties and so on. b) Multi-modality of teaching content. Multi-modal oral English teaching materials include written materials, pictures, audio, and video. For example, college students can imitate or dub for the original video clips, so that they can have the opportunity to learn authentic pronunciations, intonations and expressions, and improve their western cultural literacy. Multimodal oral teaching content should be integrated with the various video materials, oral English textbooks, audio, video, software and other cyber teaching sources, related to the theme, making teaching materials practical, interesting and diverse. c) Multi-modality of teaching method. The language itself is communicative. Teachers are giving lectures through question and answer ex- 
ercises, dialogue exercises and making statements. In addition, qualified teachers can make full use of unconventional modal symbols such as PPT, audio and video, group oral practice and role-play. In the demonstration, teachers can also use eyes, facial expressions, language tone, gesture and other non-verbal forms to cooperate with the visual modalities such as the spatial layout of the classroom to express the correct meaning effectively. If a college student goes to a hotel to study how to reserve a room, he can do inquiries, ask room facilities. He can also drink and eat in restaurants, and feel the aroma of food. The whole process is very similar to the real content. In the process of participation, different college students play different roles to form different communication results, and each participant can get their own experience and feelings. In this process, through the sense of vision, auditory, smell and touch, the students can experience different fictitious scenes to realize the multi-modality learning. However, teachers should also pay attention to the class time and try to increase the proportion of students' input and output (Pan, 2011).

\section{Conclusion}

Positive modal coordination can produce positive effects; negative mode coordination may lead to negative effects. Teachers should measure the mode from practical angle when selecting and using multimodal elements. In constructing multimodal oral English class mode, teachers should view the teaching content as the main line, screen materials with a specific target, and avoid guest usurping the host's role or putting the cart before the horse.

Multimodal teaching method is a double-edged sword. How to play its role properly and reasonably requires the constant efforts of teachers. In the long run, multimodal teaching method in the application of college oral English class has a unique advantage, which is one of the directions of the oral English teaching reform in the new period. But the researchers at home and abroad find that the research of multimodal discourse analysis theory framework and analytical methods still needs to be improved. At the same time, the teacher's own development problems in the multimodal English teaching also deserve further study.

\section{Founding}

The thesis is the research result of the teaching reform project of Baoding College-Study on the construction of multimodal interactive oral English teaching model (Project number: jg20170111).

\section{Conflicts of Interest}

The authors declare no conflicts of interest regarding the publication of this paper.

\section{References}

Gu, Y. G. (2007). Analysis of Multimedia and Multimodal Learning. Foreign Language Audio-Visual Teaching, No. 4. 
Kress, G., \& Leeuwen, T. (1996). Reading Images: The Grammar of Visual Design. London: Routledge.

Li, Z. Z. (2003). The Analysis of Social Semiotics on Multimodal Discourse. Foreign Language Research, No. 5.

New London Group (1996). A Pedagogy of Multilateral Literacies: Designing Social Futures. Harvard Educational Review, No. 1.

Pan, M. W. (2011). Communicative Competence from the Perspective of Multimodal: Reconstruction and Exploration. Shanghai: Shanghai Foreign Studies University.

Zhu, Y. S. (2007). The Basic Theory and Research Method of Multimodal Discourse Analysis. Foreign Language Journal, No. 5. 